\title{
How Voters Distort their Perceptions and Why this Matters ${ }^{\dagger}$
}

\author{
De Angelis Andrea ${ }^{\mathrm{a}}$ \\ ${ }^{\text {a }}$ Department of Political Science, University of Lucerne, Lucerne, Switzerland
}

\begin{abstract}
Voters' ability to perceive political parties' position on policy scales is a precondition for a functioning and responsive electoral democracy. Appropriate measures of policy distance are thus key to address the link between political parties and the citizens. This chapter reviews the scholarship on ideal point estimation identifying the main methodological and substantial implications for empirical studies involving issue scales. Next, the chapter applies two-stage Bayesian Aldrich-McKelvey scaling to European Election Studies data to find evidence of systematic perceptual distortions: right-wing voters perceive political parties as more progressive than they actually are, while knowledgeable voters perceive greater differences between parties. Perceptual bias is also shown to correlate with standard polarization measures based on perceived party positions.
\end{abstract}

\section{Keywords}

Electoral representation, issue positions, differential item functioning, ideal point estimation, European Elections

\footnotetext{
${ }^{\dagger}$ Corresponding author: Andrea De Angelis (andrea.deangelis@unilu.ch). The Version of Record of this manuscript has been published and is available in the Oxford Handbook of Electoral Persuasion. Citation: De Angelis, Andrea. 2020. "How Voters Distort their Perceptions and Why this Matters". In: The Oxford Handbook of Electoral Persuasion, Suhay, Elizabeth, Grofman, Bernie, Trechsel, Alexander H. (eds.). DOI: 10.1093/oxfordhb/9780190860806.013.55.
} 
Word count: 7,032. 


\section{Spatial theory and voter perceptions}

Voters' ability to perceive political parties' positions on policy scales is long recognized as a precondition for a functioning and responsive electoral democracy (Sartori 1976, 292). In particular, the party government model asserts the responsive character of electoral competition if certain conditions are fulfilled: voters must be able to cast an informed vote judging their policy distance from political parties ${ }^{2}$ (Dalton 1985). Appropriate measures of how voters perceive party positions are therefore key to address the link between political parties and citizens.

Political parties are the transmission belt of the representation process. Parties link citizens' preferences to policy outcomes, and transform preferences into policies (Dalton, Farrell, and McAllister 2011). Given the multiplicity of relevant political issues, voters tend to judge their distance from parties relying on heuristic cues that reduce the cognitive burden of orienting their voting decisions. An organizing scheme shown to signal political orientations in most countries is the Left-Right ideological dimension (Downs 1957; McDonald and Budge 2005; Dalton, Farrell, and McAllister 2011).

Left-Right position can predict opinions on many specific issues and facilitates electoral competition. In the words of Sartori $(1976,296)$ :

[Findings from ANES data supporting unidimensionality of left-right imagery] do not easily fit the Downsian model unless an additional concept is entered — positioning — under two formulations, namely, position-perception and position-image. The notion of position-perception implies that the voter places himself and the parties in some kind of spatial ordering, in a row; and the notion of position-image implies that parties manoeuvre precisely for conveying to the electorate a spatial location of themselves.

\footnotetext{
2 These conditions have been firstly identified in The American Voter: "1. The issue must be cognized in some form. 2. It must arouse some minimal intensity of feeling. 3. It must be accompanied by some perception that one party represents the person's own position better than do the other parties" (Campbell et al. 1960, p. 98).
} 
Given position-perceptions and position-images, then — but only then - can we fruitfully employ the notion of 'issue position' in an 'issue space'.

Spatial competition is thus enabled by voters' abstract projections ('position-perception') making use of political labels as convenient devices to soften the cognitive demands of evaluating parties and candidates. The Left-Right continuum fits into a more general understanding of preferences as arising from the proximity to potential options (Hotelling 1929; Black 1948; Davis, Hinich, and Ordeshook 1970). Enelow and Hinich (1984) applied the spatial theory to general elections by representing electoral competition with political labels arrayed in a linear order along predictive dimensions. Rational self-interested voters choose the preferred option (ideal point) maximizing single-peaked and symmetric utility function. Enelow and Hinich explicitly incorporate voters' perceptions, in that the usually too diffused political signals during a campaign would prevent identical estimates of the policy positions of political candidates. Conversely, voters tend to draw inferences regarding the policy meaning and the correct interpretation of the predictive labels that are fixed in the campaign. In the simplest case, voter $i$ estimates the position of candidate Theta on the underlying predictive policy dimension $\Pi$ (namely $\Pi_{\theta}$ ) using a linear function of the predictive label: $\theta_{i}=b_{i}+\pi_{\theta} v_{i}$, where $b_{i}$ and $v_{i}$ represent idiosyncratic parameters introducing heterogeneous perceptions among the voters. In particular, $b_{i}$ produces a lateral perceptual distortion, shifting the perception of $\pi_{\theta}$ towards one endpoint of the policy dimension, while $v_{i}$ produces a scale distortion, reducing or amplifying the perceived policy differences associated to a change in the true position on the predictive dimension. Different voters can therefore draw different inferences from the same party positions: "[ $[$ ]hus, political debate is framed in terms of a common set of predictive labels, but each label is given a subjective interpretation by each voter." (Enelow and Hinich 1984, 40).

The spatial model is usually contrasted with the social-psychological ("Michigan") model of voting decisions as arising from a party identification developed at an early age in a process of political socialization (Campbell et al. 1960). However, The American Voter describes party identification 
as a perceptual screen that affects how voters perceive political parties and candidates. Thus, the two models actually converge on predicting the presence of relevant perceptual differences among voters, although considering alternative conceptual frames relating heuristic reasoning and the unfolding of political identities.

Voters may therefore understand the underlying policy dimensions differently than it is generally understood: a predictive dimension, such as the Left-Right dimension, facilitates the task of assessing policy distance, but it will also lead voters to develop subjective interpretations and idiosyncrasies, resulting in a personal understanding of such dimension. Achen and Bartels (2016, 42) remind three different psychological mechanisms potentially affecting the perception of policy distances:

The first, policy-oriented evaluation, corresponds to the conventional interpretation of issue voting in the folk theory of democracy [...]. The second, persuasion, involves prospective voters altering their own issue positions to bring them into conformity with the issue positions of the candidate they favour. The third, projection, involves prospective voters convincing themselves that the candidate or party they favour has issue positions similar to their own [...].

Similar persuasion and projection mechanisms were firstly detected in the 1970s (Page and Jones 1979; contra: Markus and Converse 1979). Thorny issues of causal antecedence have dominated the discussion, hiding the substantive importance of detecting such latent heterogeneity in voters' perception. Perceptual distortion induced by persuasion and projection may be better estimated than controlled out by design: if omitting perceptual distortion can lead to substantial bias and measurement incomparability, measuring it explicitly can actually improve our understanding of electoral competition. In general, perceptual distortions have been shown to be widespread, affecting measures as diverse as job satisfaction (Kristensen and Johansson 2008) and reported HIV prevention behaviours (Gourlay et al. 2014). 
Better measures of perceived party positions may additionally contribute to soften well-known difficulties in election studies. First, following standard Left-Right self-placements, we are led to think that the median voter nearly universally occupies the middle category, which prevents dynamic and comparative assessments of her position. Second, politically unaware voters may use the middle category to avoid the discomfort stemming from 'Don't Know' answers (Volkens et al. 2013). Third, even when primed with interval scales, voters tend to use a few prominent categories leading to 'circus tent' distributions (Aldrich and McKelvey 1977). Finally, cross-country comparisons are also impeded by cultural diversity. For instance, the general Left-Right scale has different substantive meaning when applied in Western and in Central-Eastern Europe (Rohrschneider and Whitefield 2012). Comparative studies may thus inadvertently advance a strong assumption of construct invariance.

Solutions to these problems are well-understood and readily available. Psychometric techniques and measurement models are gradually becoming part of the political science toolkit. Still, the majority of empirical studies relies on predictive labels to directly infer policy positions. Such standard procedures disregard that perceptual data mixes objective policy positions and subjective meaning attached to the predictive labels. The next section adumbrates the potential solutions.

\section{Perceptual data and differential item functioning}

Voters use abstract predictive dimensions to summarize issue positions. For this reason, they may report different scores not because they denote different policy positions, but because they consider a different pool of issues, or interpret differently the latent dimension. How should we deal with such perceptual distortions?

A good measure should assign the same scores to individuals with the same values of the underlying construct. This property is known as factor equivalence, meaning absence of item bias, 
or 'Differential Item Functioning' (DIF) 3 . When the attribute being measured has a conceptual meaning that differs across subjects the property of measurement invariance may be undermined and DIF arise (Osterlind, Everson, and Osterlind 2009). Since observed differences may reflect subjective idiosyncrasies rather than true differences in the underlying construct, the differential functioning of measurement items will invalidate direct comparisons (Davidov et al. 2018; Lee, Little, and Preacher 2018). The reason why voters experience differently latent constructs may depend on individual, group, or country-specific factors (Bond and Fox 2015, Ch. 5). Thus, psychometric considerations go along with substantial concerns since group and political identities may distort voters' perceptions of predictive labels.

Measurement theory and latent variable modelling can contribute to improve measures of policy scales and latent concepts. Contributions in this large field include 50 years of work on Multidimensional Scaling (MDS), that provides graphical representations of similarity data in terms of a set of principal coordinates on a spatial map, and Optimal Classification, a non-metric unfolding technique). The mathematical counterpart of graphical representations such as MDS was developed in psychometrics and psychology (Modern Mental Test Theory), leading to Item Response Theory and Latent Trait models (Rasch 1960; Andrich 1988; Baker and Kim 2004; Bond and Fox 2015). IRT models differ from classic Likert scaling in that they interpret the probability of a response not only as a function of features of the test-taker, but explicitly include features of the items used in the rating process. In classic applications to uncover test-takers' latent ability or intelligence, IRT models jointly produce parameters for test-taker's ability and item features (i.e. difficulty in the one-parameter IRT, or Rasch model).

In the early 1980s, political scientists Keith Poole and Howard Rosenthal integrated Random Utility theory (McFadden 1976), Optimal Classification, and the spatial theory of voting, to develop a 'basic-space' model of parliamentary voting (Poole and Rosenthal 1997; Poole 2005). Their model

\footnotetext{
${ }^{3}$ Measurement incomparability is known as (lack of) factorial invariance in the SEM literature, but in the Item Response Theory and Classic Test literature the expression Differential Item Functioning is preferred.
} 
produces estimates of legislators' ideology scores (ideal points) from parliamentary voting. Ideal points have later been estimated from various data sources, from party manifestos (Slapin and Proksch 2008), campaign finance data (Bonica 2014), and Twitter followers (Barberá 2015).

There are reasons to prefer hard choice data over reported perceptual data. Scholars, however, often cannot rely on observed behavioural data and are left with reported perceptual data, exposing themselves to systematic item bias. Solutions to amend individual measures from DIF have long been proposed, and include scaling methods (Aldrich and McKelvey 1977), latent variable models (Treier and Jackman 2008) and methods to 'glue' together actors and settings, such as anchoring vignettes and bridging observations (King and Wand 2007; Shor, Berry, and McCarty 2010; Bakker, Jolly, et al. 2014).

Aldrich and McKelvey's (1977) scaling (A-M) allows to uncover and correct for perceptual distortions in items measuring positions on policy scales. The A-M scaling model follows the spatial voting formulation describing perceptual data as a two-stage process: first, individual $i$ draws a perception of item $j$, then she reports her perception incorporating a (linear) perceptual bias. (Hare et al. 2015) develop a Bayesian version of A-M scaling to compute uncertainty scores for the individual parameters. (Lo, Proksch, and Gschwend 2014) use party membership in European Parliament's groups as anchoring observations to correct for cross-country distortions and to recover a European common ideological space.

Individual and country-specific distortions of this type violate the assumption of direct comparability, potentially biasing measures of policy positions, as well as of aggregate measures produced using these biased indicators. Polarization indices based on perceptual data may suffer from systematic measurement error, since objective party positions would also contain the subjective element of voters' perceptual distortions. In particular, (Hare et al. 2015) advance the hypothesis that many self-described centrist voters may actually be 'illusory moderates' inflating the median category. 


\section{A Two-Stage Bayesian Aldrich-McKelvey Scaling Model}

This section introduces a two-stage Bayesian Aldrich-McKelvey (2S-BAM) scaling algorithm to estimate comparable issue positions of voters and parties in European election studies, where both individual perception bias and country-specific distortions can affect measures of issue position. The algorithm is presented in heuristic terms but interested readers can find a formal mathematical formulation in the Appendix.

The algorithm is articulated in two successive (non-iterative) stages. The first stage, is a country-bycountry Bayesian implementation of A-M scaling, which computes individual-level perceptual distortions parameters within-country. In the second stage, the algorithm applies the identification strategy introduced in (Lo et al. 2014), exploiting the membership of national political parties in the European Parliament's political groups to bridge across party systems and to retrieve the European Common Space.

The first stage of the algorithm models voters' reported perceptions of party positions, $y_{i j}$, as a linear function of the true (but latent) party positions $y_{j}^{*}: y_{i j}=a_{i}+b_{i} y_{j}^{*}$. Rather than being immediately used to compute party positions with a mean score, perceived party positions are preprocessed to extract the subjective component of individual perceptions from the objective component of real party positions. To this end, the matrix of reported party positions is modelled as a function of three latent quantities: $a_{i}, b_{i}$, and $y_{j}^{*}$. The former two are the individual-level latent perceptual distortions, with $a_{i}$ representing a location parameter, and $b_{i}$ a scale parameter; $y_{j}^{*}$ indicates the latent position of party $j$ (ideal point).

Parameters $a_{i}$ and $b_{i}$ respectively represent a lateral/shift and a stretch/scale perceptual distortion. For instance, considering a Left-Right continuum, a positive (negative) value of $a_{i}$ corresponds to an individual perceiving political parties as being more ideologically conservative (progressive) than they actually are. The objective position of the party is inferred from the estimated ideal point $y_{j}^{*}$. Moreover, the latent slope $b_{i}$ captures how voters read differences on the policy space: the 
parameter indicates the change in voters' perceptions associated to a one-unit change in the latent position of party $j$. Thus, a value of $b_{i}$ larger (smaller) than one, implies that a one-unit distance in terms of the ideal points' metric is perceived by voter $i$ as a policy difference larger (smaller) than one unit, which, in turn, is associated with a stretched (compressed) perception of the underlying political space.

In this first stage, the voter perceptions are all anchored together by the A-M algorithm. Thus, all estimated parameters are mapped on the same latent metric by using party ideal points as reference values, and simultaneously estimating all quantities. Since the latent parameters are not directly observed, there is no inherent metric to measure them, and this usually leads to set constrains, either on the distribution of the latent variables, or by setting a unit to a fixed arbitrary value. This decision only affects the reference metric, but does not affect how the model first the data. Setting a standard-normal metric for the basic space has the advantage to be easily interpreted as a standardized regression coefficient and is the chosen metric in this application. The Appendix further documents the selection of prior distributions and the possibility to account for heteroskedastic error (Lauderdale 2010).

The first stage of the algorithm provides estimates of party ideal points and individual distortion parameters. At this point, the analyst has the possibility to use these measures to meaningfully compare voters and parties in a certain country. In particular, one can resort to the subset of voters that, next to the reported positions of political parties, have also reported their own position on the considered predictive dimension. The perceptual distortion parameters represent how the individual voters perceive the policy dimension and are already mapped in the same metric of the party ideal points. Thus, it is possible to apply a simple linear transformation to the voters' left-right selfplacements to achieve their position mapped on the latent space: $y_{i}^{*}=\frac{y_{i}-a_{i}}{b_{i}}$, where $y_{i}$ is the raw self-reported left-right value, and $y_{i}^{*}$ is the individual voter ideal point. The latter is already amended by perceptual distortions and can therefore be meaningfully compared to the other (parties' and voters') ideal points. 
Applying the first-stage of the algorithm amends voters' and parties' positions from perceptual bias, which is a sound strategy in single-country studies. In a comparative setting, however, additional biases may arise. This is particularly the case with large comparative studies pooling together diverse countries. A classic of such cases is the study of issue voting in the European Union context (Franklin, Mackie, and Valen 1992; Van der Eijk et al. 2006; Dalton 2017). Indeed, historic legacies, institutional specificities and different political cultures can introduce country-specific distortions confounding comparisons of voters' and parties' in different countries. This corresponds to the case where two parties with identical policy packages are actually perceived as having different positions due to the different context. For instance, a political party supporting women's free choice on abortion is likely to be perceived as moderate in countries that already grant abortion rights, than in countries that consider abortion illegal. Similarly, a party placed by Dutch voters at the central value (5) on the Left-Right scale may not share the same ideological placement of a party placed by Hungarian voters on 5 .

We therefore need the second-stage of the algorithm to amend party and voter positions from this additional source of DIF. However, if in the first stage the A-M algorithm could automatically anchor voters and parties, given that within a country parties are generally visible to all the voters, the same does not apply in a comparative context, since different parties run at elections in different countries and voters are not asked to rate, nor supposed to be knowledgeable about, the positions of foreign political parties. We therefore need to apply leverage on some kind of bridging information that allows to connect all the country-specific policy spaces. Solutions to this end may involve using comparative data of expressed preferences, such as using European Parliament legislative votes (Hix, Noury, and Roland 2006), party manifestos (König, Marbach, and Osnabrügge 2013), or expert scores (Bakker, Edwards, et al. 2014). Using external data, however, would create a disconnect with actual voters' perceptions. Approach that allows to use voters' perceptual data usually introduce interinstitutional or interstate bridge. For instance, in the U.S. context, (Poole and Rosenthal 1997) have anchored each Congress and Senate over time using congresspersons serving 
for more than one mandate, under the assumption that their ideological position would be constant over time. Poole (2005) uses members of Congress that served in other institutions to bridge across different institutional settings. In the European setting, Lo et al. (2014) use national parties' membership in the political groups of the European Parliament bridge across European Union countries. To the extent to which this decision is driven by policy motivations, one can consider this additional source information to estimate comparable party positions, estimating country-specific distortion parameters that allow to retrieve the European Common Space. This enables direct comparability of policy positions across countries, also returning estimates of the positions of the European Parliament's political groups.

In this application on EU countries I rely on the latter strategy, and therefore introduce information about the membership in the EP of national parties in the second stage of the algorithm. This way, it is possible to re-estimate the Bayesian A-M model using the matrix of party ideal points estimated in the first stage, rather than the matrix of voters' perceptions of political parties. Using the now familiar linear distortion function, the second-stage is represented by: $z_{k m[j]}=c_{k}+d_{k} z_{m}^{*}$, where $z_{k m[j]}$ is the (first-stage) ideal point of party $j$, member of the EP group $m$, in country $k$. One problem that arises in this context is that, differently from the first stage, one country can have more than one party, or none, in a certain EP group. Lo et al. (2014) adopt a frequentist bridging procedure introduced by Groseclose et al. (1999), which does not allow these missing and/or multiple occurrences. To alleviate these issues, I instead present a hierarchical adaptation of the Bayesian A-M model previously introduced (De Angelis 2017), which allows to nest party $j$ by EP groups (justifying the hierarchical notation $[j]$ ). Once again, the matrix of (first-stage) ideal points $Z_{k m[j]}$ is modelled as a function of three latent parameters: $c_{k}$ is a country-specific lateral shift distortion parameter; $d_{k}$ is a country-specific scale distortion, and $z_{m}^{*}$ is the ideal point of EP group $m$. Similarly to the first stage, the algorithm concludes by mapping all scores on a common European metric via linear transformation. 


\section{Estimation}

Estimation is conducted in a fully Bayesian framework, in which parameters are simultaneously drawn from the joint posterior distribution via MCMC simulations. Bayesian scaling models preserve the core-logic of the AM algorithm providing three important advantages: greater flexibility and ease of estimation; ability to produce uncertainty measures for all parameters; and the inclusion of respondents reporting missing answers. For greater detail on the estimation procedure refer to the Appendix.

\section{Data}

The 2S-BAM model is applied to detect perceptual distortions of Left-Right ideology and, given the recent politicization of the issues relating the European Union (Hutter, Grande, and Kriesi 2016), of the position towards European integration. Among large comparative surveys, the European Election Survey (Schmitt, Hobolt, Popa and Teperoglou 2015) is the only one asking party positions on both dimensions ${ }^{4}$. EES data are collected for the specific purpose of studying political behaviour and participation in European Parliament elections. The present analysis considers 54 elections, considering the 2009 and 2014 EP elections in 27 countries $^{5}$. The dataset is suited for large comparative studies by reason of its homogeneous methodology and consistent structure, and represents an established data source for comparative studies of political polarization (Lachat 2008; Lo, Proksch, and Gschwend 2014; Vegetti 2014) ${ }^{6}$.

\footnotetext{
${ }^{4}$ The Comparative Study of Electoral Systems (CSES) does not consider a harmonized second dimension and thus we would be limited to the analysis of the left-right dimension. The same problem holds for the European Social Survey (ESS). At the time of writing there was no harmonized comparative dataset of Europe-wide national elections.

${ }^{5}$ Overall, the 2014 version collected about 30,000 interviews (approximately 1,100 interviews for each member state, with the exceptions of Luxemburg and Malta, with about 500 respondents, and the U.K. with about 1,300 interviews) via Computer Assisted Personal Interviews. EES 2009 collected approximately 27,000 interviews, about 1,000 per member state) via Computer Assisted Telephone Interviews.

${ }^{6}$ Regrettably, the data contains a factual error in the question wording for the EU integration item in the EES 2014. This error was corrected with a supplementary EES 2014 study (Schmitt, Popa, and Devinger 2015). This study allows estimating party ideal points, and consequently of the
} 


\section{$4 \quad$ Mapping perceptual bias and voter ideal points}

This section presents descriptive visualizations for part of the large set of parameters that was estimated. The focus is maintained on voters' perceptual distortions and ideal points, so estimates of the party ideal points, country-level distortions, ideal points of the European party families, as well as of the variance parameters, are not documented. Descriptive summaries are also limited to the Left-Right dimension.

We first inspect estimated lateral shift distortions: Figure 1 reports the median posterior draws of the shift distortions of European voters, disaggregated by country, in 2009 and 2014. Countries are sorted by the median shift distortion, which is reported in the figure. Direct comparability of voters' positions would require these values to be constant, or at least similar across voters, but inspecting Figure 1 this assumption seems unlikely to hold on empirical grounds. Indeed, substantial perceptual variation is manifest: in every country, some individuals consistently shift perceived party positions to the left $\left(a_{i}<0\right)$, whilst others shift party perceptions to the right $\left(a_{i}>0\right)$. Moreover, we also note considerable variation across countries: the median value of lateral shift parameters ranges between the -0.79 in Spain (2014), suggesting that Spanish voters tend to misperceive political parties as more conservative than they actually are, and the +0.89 in Slovakia (2014). To better interpret these shifts, a 1-unit distance on the European common space corresponds to the distance between the position of the German SDP $(-0.48)$ and the position of Die Linke -1.47 . These parameters capture incomparability between individuals (within-country) and should be separated from the cross-country incomparability estimated in the second-stage of the model (arising from the fact that the national policy spaces are not linked).

polarization indices, but it does not include many individual features to study the determinants of perceptual distortions, and thus individual parameters for the EU dimension in 2014 were not estimated. 
We can similarly inspect also the scale (stretch) distortions for the Left-Right dimension: Figure 2 reports the distribution of the median posterior draws of individual scale distortions for each considered country.

Scale distortions occur when voters conceive the political space with different unit metrics. When $b_{i}=1$ a one-unit distance in party positions is perceived as one-unit distance by voter $i$; but if $b_{i}<$ $1\left(b_{i}>1\right)$, then the voter will underestimate (overestimate) policy distances. Thus, voters with low $b_{i}$ do not discriminate well between party positions (i.e. their reported positions tend to lump parties together) and if $b_{i}<0$, then the voter does not correctly perceive the ordering of party positions (this may be used as operational definition of 'non-ideologues' for the Left-right dimension). Thus, the aggregate value of these $b_{i}$ conveys important information about dimensional saliency in the country. As in the case of lateral shift distortions, we find evidence of systematic perceptual distortion affecting voters' subjective metric of the ideology space.

Finally, we can compute comparable ideal points linearly transforming Left-Right self-placement: $y_{i}^{*}=\left(L R_{i}-a_{i}\right) / b_{i}$. By applying this transformation to the subset of voters who did report their Left-Right position, we obtain the distributions displayed in Figure 3. 
Figure 1 Distribution of voters' Left-Right lateral shift distortions (2009 and 2014)

Empirical distributions of voters' Left-Right shift distortions (EES 2009)

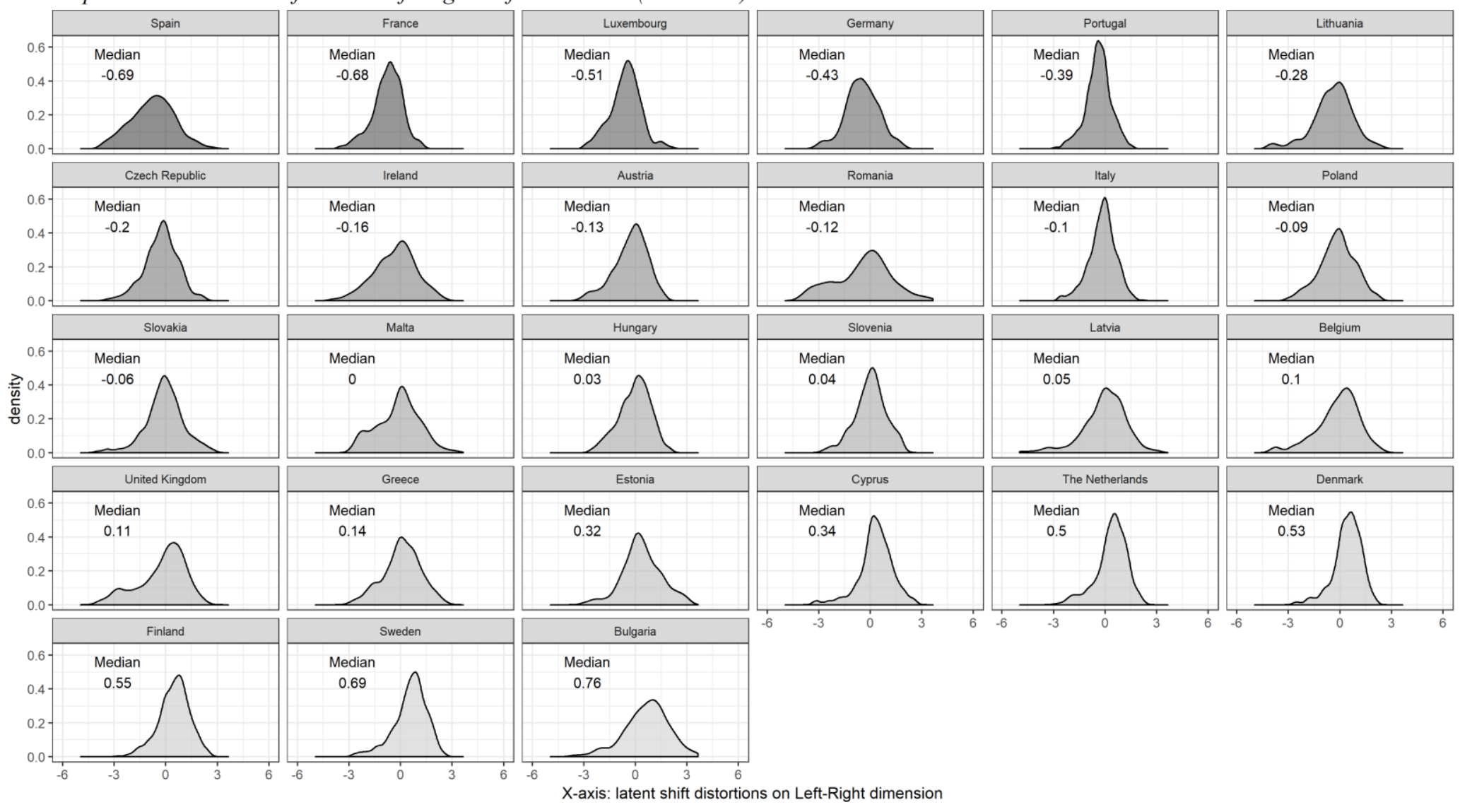


Empirical distributions of voters' Left-Right shift distortions (EES 2014)

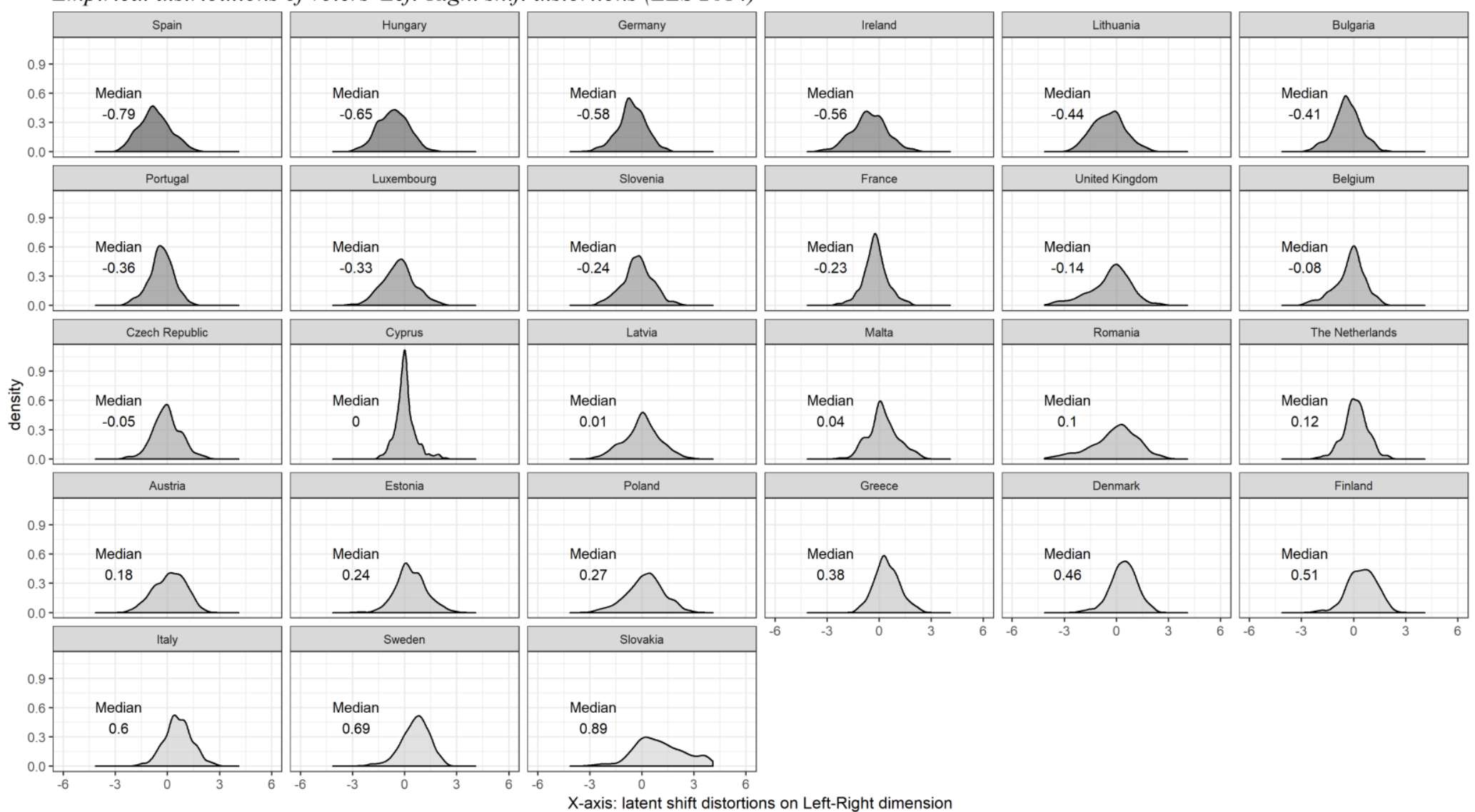

Note: density plots represent the empirical distributions of median posterior draws of lateral shift distortions parameters on the Left-Right dimension as estimated through the $2 S$-BAM procedure. 
Figure 2 Distribution of voters' Left-Right scale distortions (2009 and

Empirical distributions of voters' Left-Right scale distortions (EES 2009)

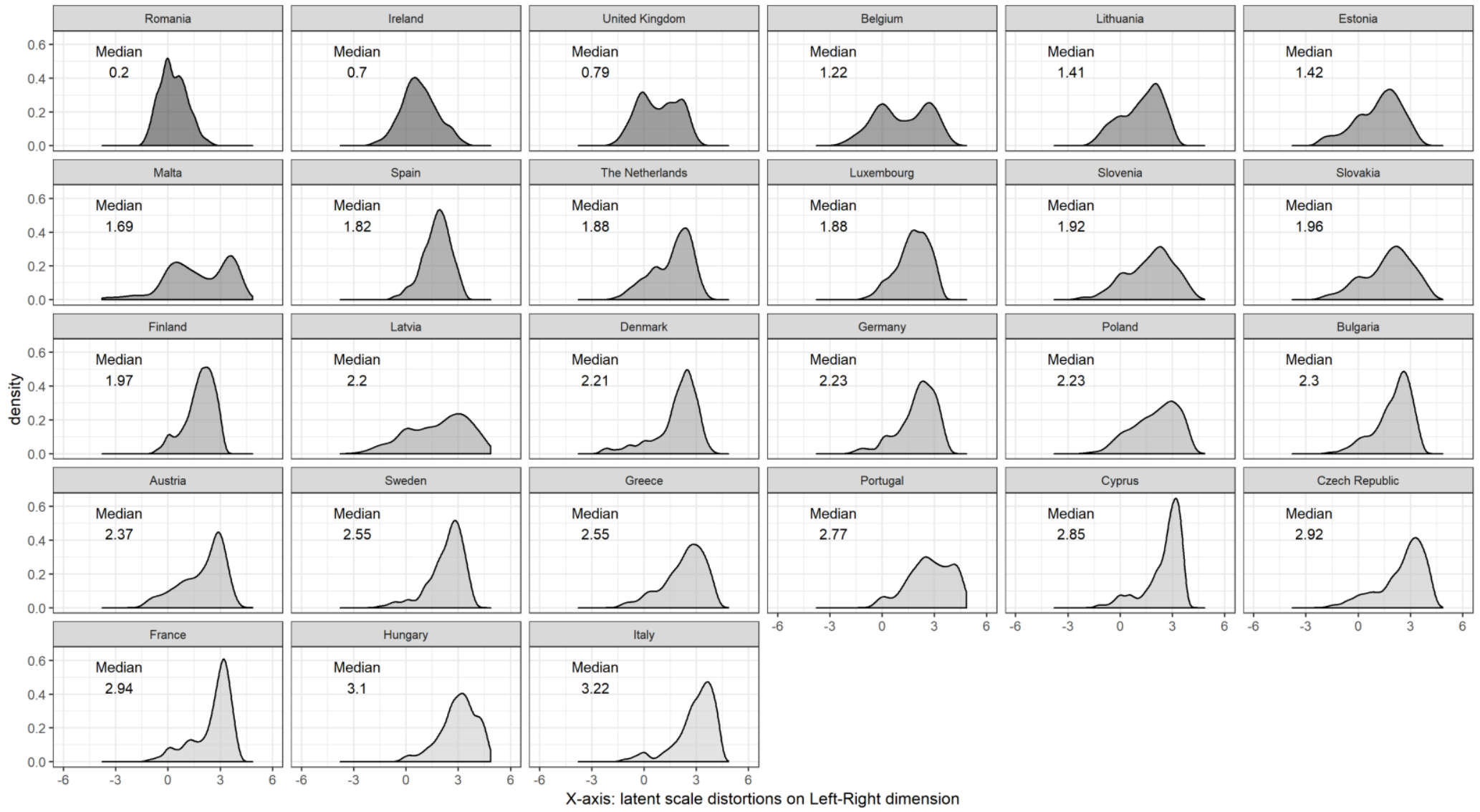


Empirical distributions of voters' Left-Right scale distortions (EES 2014)

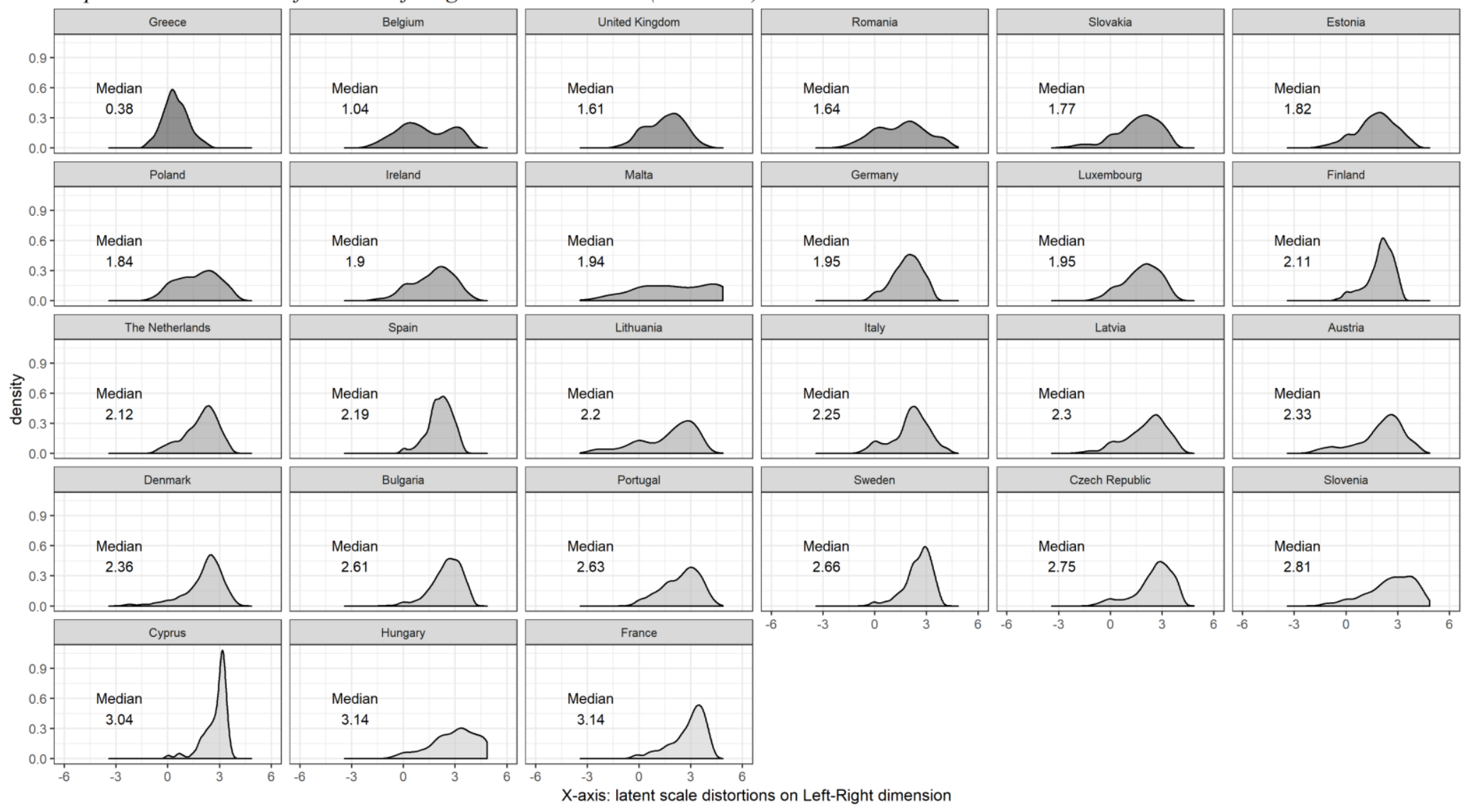

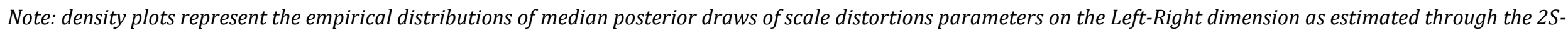
BAM procedure. 
Figure 3 Distribution of voters' Left-Right ideal points (2009 and 2014)

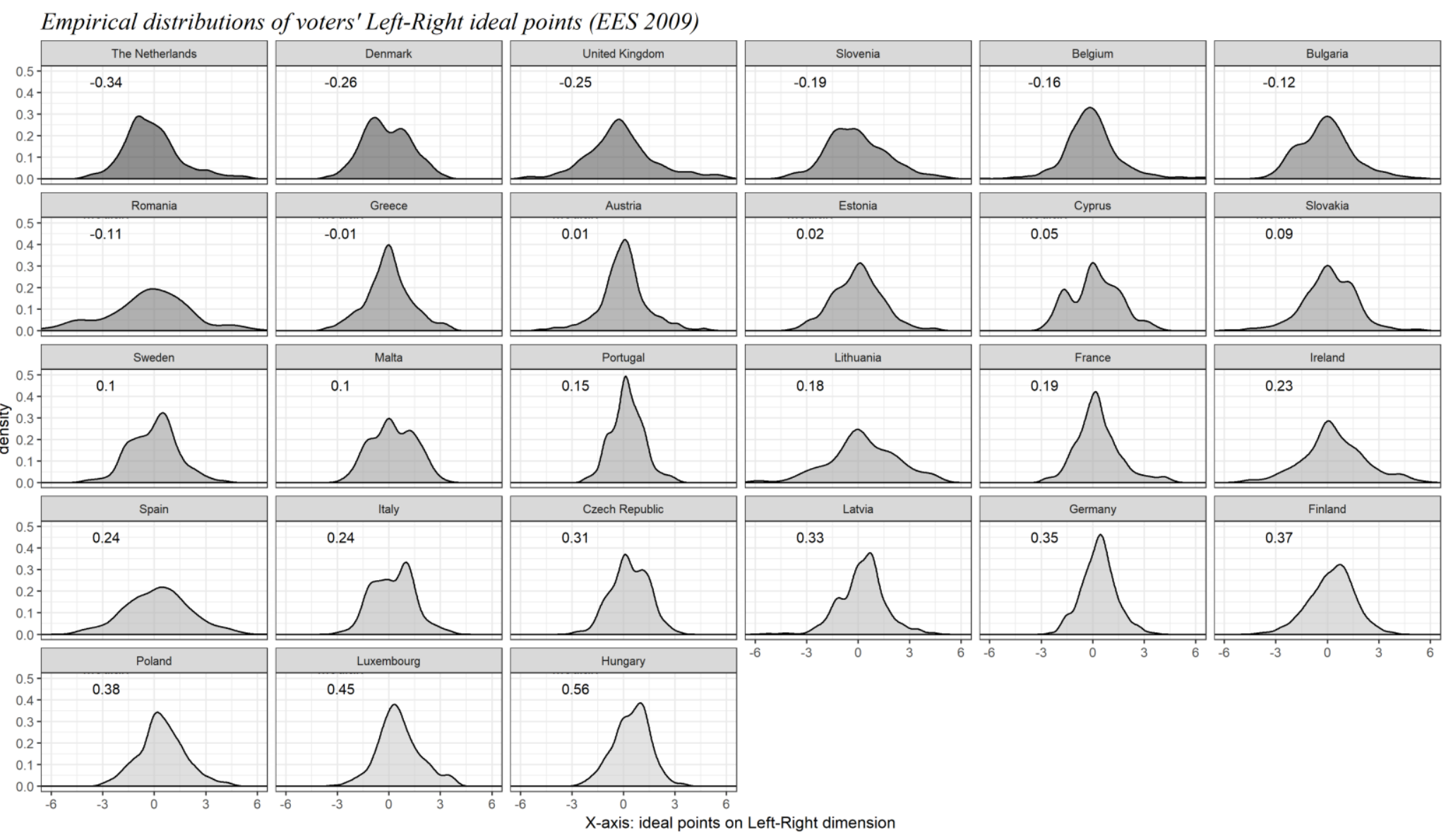


Empirical distributions of voters' Left-Right ideal points (EES 2014)

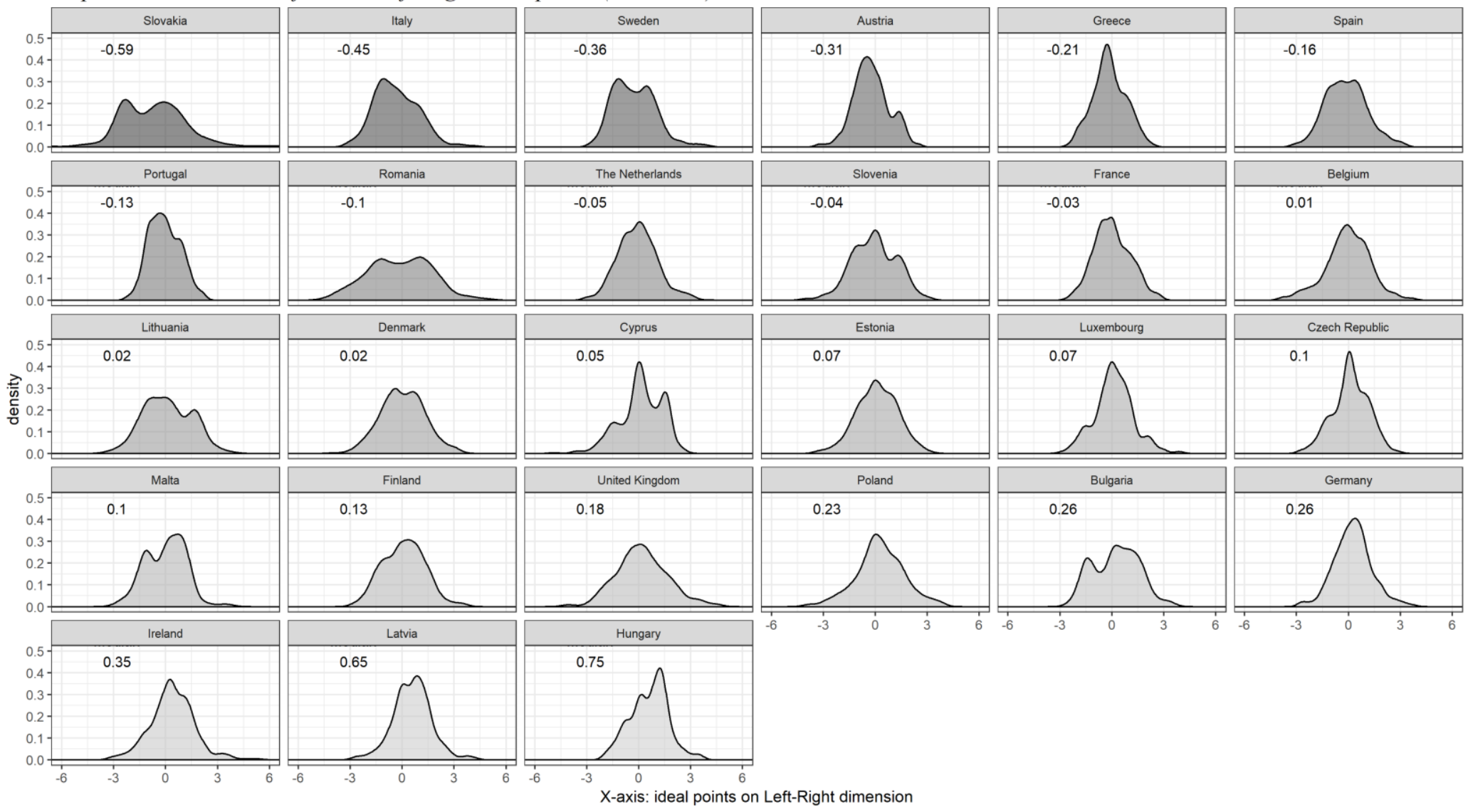

Note: density plots represent the empirical distributions of voters' ideal point on the Left-Right dimension as estimated through the $2 S$-BAM procedure. 
Countries are sorted by median ideal point in the country, i.e. the estimated 'median' voter. Nevertheless, central tendencies are not equally meaningful due to the varying degrees of unimodality and dispersion in the empirical distributions of the different electorates. Ideal points are directly comparable because they are all explicitly mapped on the same basic space, so they allow for direct comparison among voters, and between voters and parties' positions.

Strikingly, the empirical distributions of voters' ideal points reveal a remarkable level of latent variation, in terms of both shape and dispersion of voter positions. Broadly speaking, and similarly to what has been observed for the Unites States' electorate (Lelkes 2016), the ideal points' distributions appear in most European countries as (perfectly or imperfectly) unimodal, signalling relatively low levels of overall mass polarization. Yet, while in some countries the electorate displays leptokurtic distributions - thin tails and high central peaks signalling relatively low mass polarization - in other cases we observe platykurtic flat distributions with heavy tails (e.g. Spain and Italy) suggesting larger mass polarization levels. Indeed, in some cases violations of unimodality are particularly evident, either due to small local peaks in the distribution, or because of the flat shape of the distribution. These cases signal stronger ideological clustering and/or diversity. Visual inspection reveals various cases of flatter distributions, and cases of distributions with local peaks leaning towards bi- or multi-modality (e.g. the trimodal Cyprus, to a lesser extent Sweden, Malta, Hungary, Slovakia and Bulgaria). We also learn that electorates' preference distributions are generally not symmetrical. ${ }^{7}$ Finally, if we had to estimate the position of the median voter by computing the median value of the reported Left-Right position, the result would return ' 5 ' in all cases, except Hungary, Poland, and Finland (2009) returning '6', which, also considering the presence of large right-wing Eurosceptic parties like Fidesz in Hungary, PiS in Poland, and the True Finns in Finland, are in fact the cases in which one would expect the median voter to lie to the right of the center.

\footnotetext{
7 The Italian (2014) and Austrian (2014) distributions resemble the stylized right-skewed distribution discussed in Downs $(1957,121)$.
} 
These summary considerations are by no means exhaustive and aim at presenting the estimated parameters as well as to outline the unexplored potential usages of A-M scaling in electoral research.

\section{$5 \quad$ Are perceptual distortions systematic?}

Why do voters misperceive political parties' stance? Is this source of measurement incomparability resulting from random processes, or is it systematic and can therefore be predicted? Panel data designs generally account for such idiosyncratic time-invariant effects (such as scale distortions) by means of fixed-effects. By adopting the Aldrich-McKelvey framework, however, it is possible to achieve explicit estimates that make it possible to directly study such perceptual distortions. This section provides an exploratory assessment of the correlates of shift and scale distortions.

\section{Predicting lateral shift distortions}

I hypothesize that shift distortions derive from different perception of the endpoints of the political space rooted in the group-identity theory and in the mechanisms of persuasion and projection previously outlined. In particular, ingroup favouritism and outgroup negativity could lead voters to report perceptions that are systematically favourable to the former and unfavourable to the latter. In the light of moderation bias, we may conjecture that ideologically extreme voters will underestimate their own extremism. Moreover, one would expect this relationship to be moderated by partisan identification, political knowledge and interest in politics. Partisan, motivated and knowledgeable voters may be incentivized, or better able, to favour their own position by tilting the policy space towards the opposite endpoint: this way, they would appear as having a more moderate stance, while distant parties would also be perceived as more extreme.

These conjectures are tested using the (median posterior draws of) latent parameters $a_{i}$ as dependent variable. The main expectation is that left-wing (right-wing) voters are associated with 
positive (negative) shift distortions, implying a negative correlation between Left-right position and shift distortions. A set of linear hierarchical models, with voters nested within elections, are used to test this proposition. The baseline model considers an extensive set of statistical controls, including basic demographic information (age, gender, education, occupation), as well as socio-demographic features linking to classic political cleavages (religious denomination, frequency of attendance to religious services, urban residence, social class, union membership, and a proxy for income level). The baseline model also includes cognitive resources and motivation, operationalized with factual political knowledge and interest in politics, and the strength of party identification (from nonpartisan to strong partisan). Greater detail is provided in the Appendix.

Model 1 adds a linear and quadratic terms for the voters' ideal point position (operationalizing their ideological position). Model 2 explores the interactions between these linear and quadratic terms and party identification. Models 3 and 4 repeat the exercise interacting linear and quadratic ideology respectively with interest in politics and with the level of factual political knowledge.

Model coefficients are reported in Appendix, while Figure 4 reports average predictive comparisons from the four models.

The estimates lend support to the previous conjecture, although the predictive ability of the models is actually asymmetric and points towards larger shifts towards the left. In fact, right-wing voters on average misperceive party positions up to three basic-space units away from the centre. On the other hand, moderate and left-wing voters seem to perceive parties rather accurately, although subpopulations of strong left partisan, highly motivate and knowledgeable left-wing voters also tend to tilt the ideology space towards the conservative side. On the right-side of the ideological spectrum, on the other hand, there are no large predictive differences between sub-populations, although strong right-wing partisan appear to shift less the political spectrum than right-wing independents, which runs against prior expectations. 

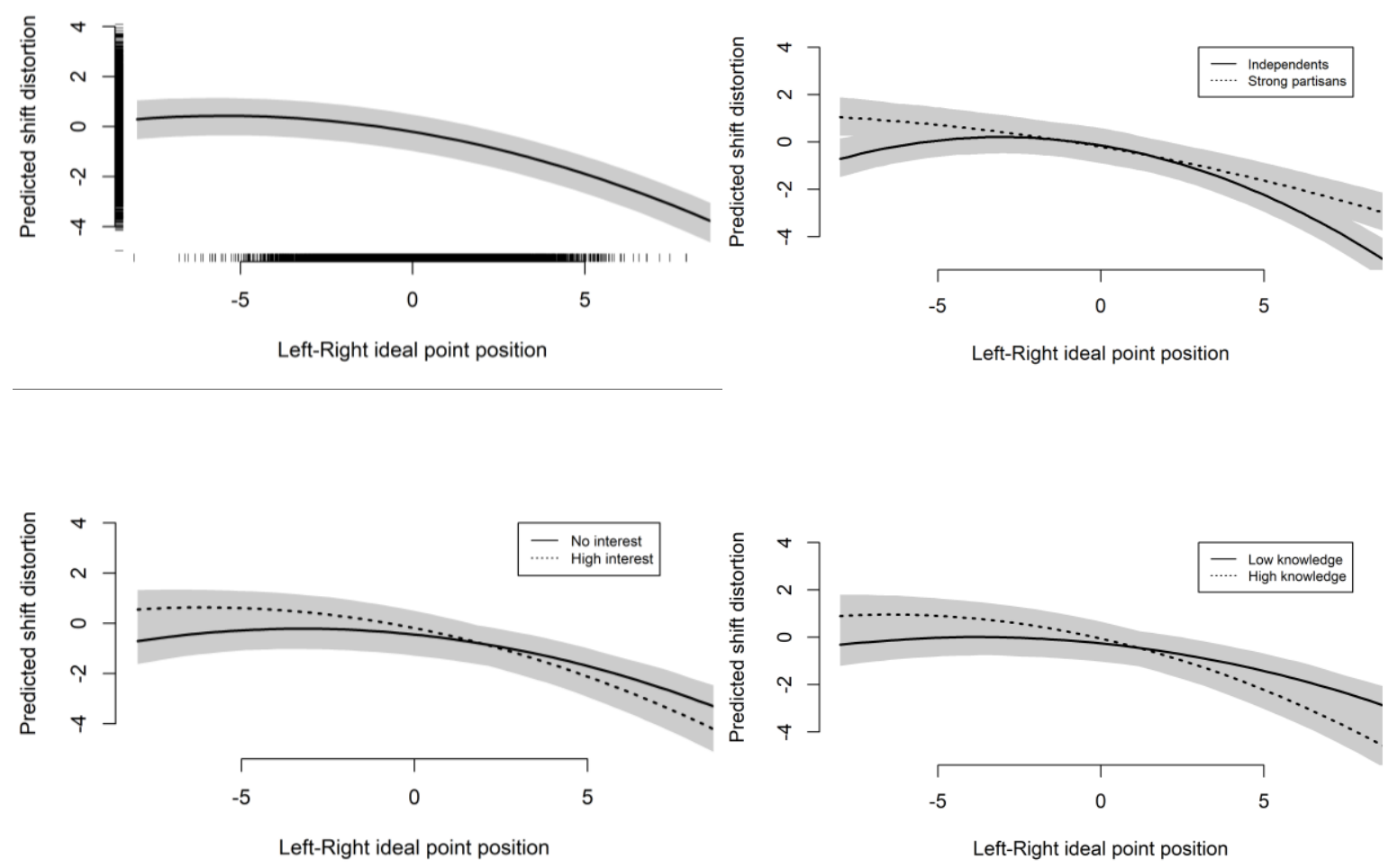

Note: predicted values of lateral shift distortions (95\% confidence intervals computed via Monte Carlo simulations). Models are reported in Appendix.

A possible explanation for this unexpected result is that extreme-right voters may not feel threatened in their integrity by the acknowledgment of their extremism, and thus do not display the signs of moderation bias.

\section{Predicting scale distortions}

Scale distortions fundamentally represent the ability to discriminate between party positions. Knowledge is a basic requisite for the ability to differentiate, and thus the main expectation is that politically knowledgeable voters should stretch the policy space, while politically unaware voters may tend to perceive parties as similar. A similar mechanism may be also triggered by the personal interest in political matters, which may lead to better differentiate party positions. At the same time, the same group-identity mechanism that was shown to affect lateral distortions may play a role in explaining scale distortions, since a contemporaneous shift may not cancel out: we may expect 
partisans to shift the other side towards the extreme more than their own side towards the centre. A similar mechanism may be conceived also for moderate vis-a-vis more ideologically extreme voters, independently of their party identification.

Figure 5 summarizes the predictions from the four models (coefficient estimates are reported in Appendix). The impression is that indeed more knowledgeable voters tend to better differentiate between parties, with knowledgeable strong partisans doing so to a larger extent. Differently, the interest in politics has a minor predictive ability, and ideological position do not make a difference in predicting scale distortions.

Figure 5 - Predicting Left-Right lateral shift distortions
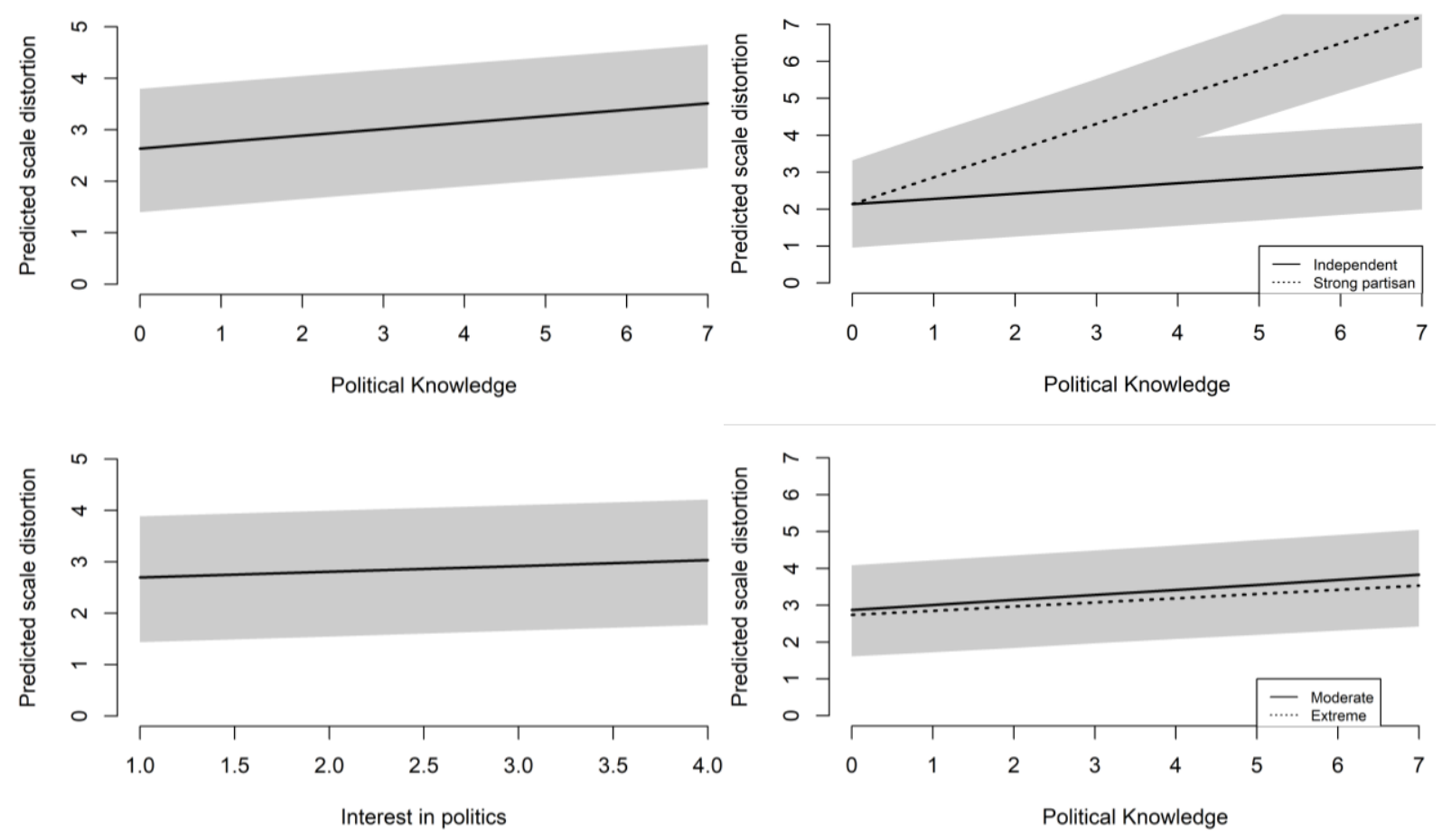

Note: predicted values of lateral shift distortions (95\% confidence intervals computed via Monte Carlo simulations). Models are reported in Appendix.

\section{Predicting distortions on the EU dimension}

The same expectations are tested also considering the EU integration dimension. As recalled, samples are limited to the 2009 wave only. Figure 6 shows similar results to the Left-Right case. 
Figure 6 - Predicting lateral shift and scale distortions on the EU dimension
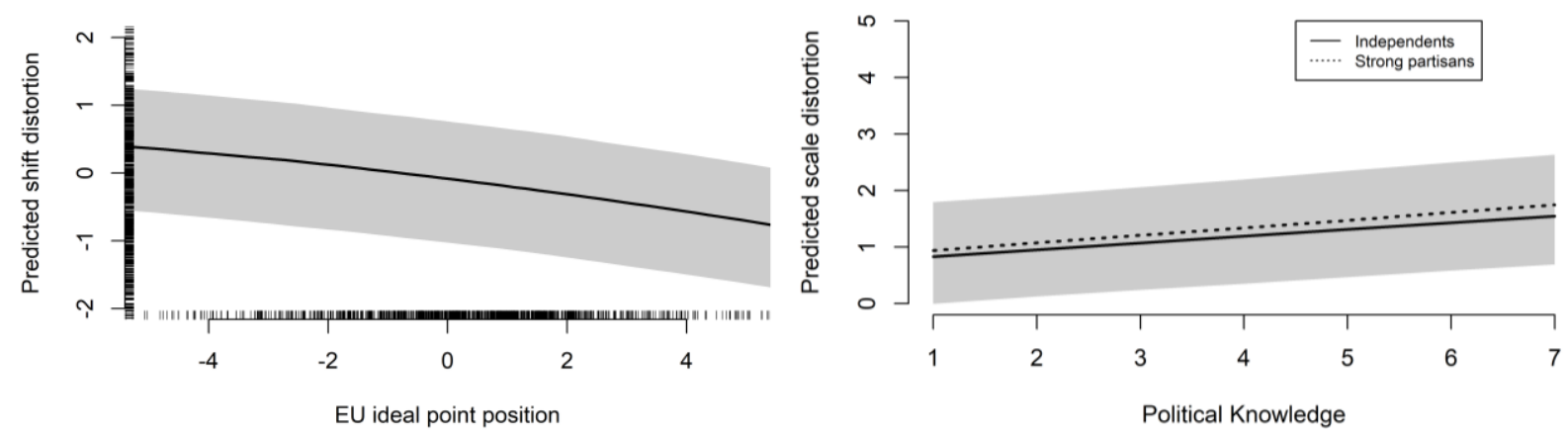

Note: left pane displays predicted values of lateral shift distortions as a function of voters' ideal point on the EU integration dimension. The right pane shows predicted scale distortions as a function of political knowledge for independent and strong partisans (95\% confidence intervals computed via Monte Carlo simulations).

We still find that lateral shifts on the EU dimensions are predicted by the underlying position on the EU, with pro-European voters perceiving parties as more Eurosceptic. However, in this case the relationship is approximately linear. On the other hand, we find that political knowledge still predicts scale distortions, although to a somewhat minor extent. This may point to a strategic ambiguity on the side of the parties. Finally, the differential perception between knowledgeable independents and partisans is not detected on the EU dimension.

\section{Perceptual bias and polarization}

This section shows how systematic perceptual bias may travel to aggregate-level measures computed with reported positions. In particular, I consider the case of polarization indices, and computing the weighted standard deviation introduced by Dalton (2008), using respectively standard (raw average of party positions) and 2S-BAM (party ideal points) measures, for Left-Right ideology and the position towards EU integration.

Having shown that perceptual distortions correlate with important cognitive and political predictors, the suspicion is that systematic bias, mixing objective positions with subjective perceptions, may travel from individual perceptions to party positions, to inflate also aggregate indicators. For 
instance, it is possible that varying shares of ideological, partisan and/or knowledgeable voters in the electorates may systematically bias the estimates of party positions in the party systems.

Since larger scale distortions lead to overestimate party distances, one possibility is that scale distortions may bias polarization indices ${ }^{8}$. We investigate this possibility reassessing scale distortions $\left(b_{i}\right)$ in the European electorates, and relating these estimates to two different measures of polarization: a standard Dalton (2008) index $\left(P I_{k}\right)$, computed with raw average perceptions of LeftRight and EU party positions weighted by party vote shares; and a version of the Dalton (2008) index constructed with the ideal points of party positions $\left(P I_{\text {Ideal }, k}\right)$ in place of the standard averages. All previous controls are included with additive specification. The expectation is that DIF may confound the standard Dalton index, thus we expect that larger polarization is associated with larger $b_{i}$. On the other side, a polarization index computed on the ideal points should be uncorrelated with voters' scale distortions, since objective and subjective components are explicitly separated in the 2S-BAM algorithm. Moreover, a control for the effective number of electoral parties (ENEP) in the party system, as well as random effects at the election level are included. The same regression is applied to the Left-Right and the EU integration dimension, although for 2009 only in the latter case. The following Table 1 presents a selection of coefficients for the polarization indices from the models reported in Appendix.

One-standard-deviation increase in the standard polarization index on the Left-Right and on the EU integration dimension are associated respectively with an increase of scale distortions of $\beta_{L R}=$ $0.29(p<.001)$, and $\beta_{E U}=0.31(p<.001)$. On the other hand, the coefficients of polarization indices computed with 2S-BAM party ideal points are strikingly small and statistically not significant. Thus, the evidence points at ideal points as amending the measurement bias stemming from voters' subjective interpretation of the latent scales. Differently, standard polarization indices merge two things: voters' subjective interpretations of the scales, and objective polarization

\footnotetext{
${ }^{8}$ Scale distortions operate stretching the basic space, and in this sense are more directly linked to polarization. An alternative specification could be to consider the absolute value of latent shift distortions, $\left|a_{i}\right|$.
} 
stemming from party positions.

Table 1 - Polarization and scale distortions

\begin{tabular}{|c|c|c|c|c|}
\hline \multirow[b]{2}{*}{$\mathrm{DV}: b_{i k}$} & $\begin{array}{l}\text { Model } \\
\text { (1) }\end{array}$ & $\begin{array}{l}\text { Model } \\
\text { (2) }\end{array}$ & $\begin{array}{l}\text { Model } \\
\text { (3) }\end{array}$ & $\begin{array}{l}\text { Model } \\
\text { (4) }\end{array}$ \\
\hline & $\begin{array}{l}\text { Polarization } \\
\text { index, LR }\end{array}$ & $\begin{array}{c}\text { Polarization } \\
\text { index on ideal } \\
\text { points, LR }\end{array}$ & $\begin{array}{l}\text { Polarization } \\
\text { index, EU }\end{array}$ & $\begin{array}{c}\text { Polarization } \\
\text { index on ideal } \\
\text { points, EU }\end{array}$ \\
\hline \multicolumn{5}{|c|}{ Polarization index } \\
\hline$P I_{L R}$ & $\begin{array}{c}0.29^{* * *} \\
(0.20-0.38)\end{array}$ & - & - & - \\
\hline$P I_{\text {Ideal }, L R}$ & - & $\begin{array}{c}-0.03 \\
(-0.14-0.09)\end{array}$ & - & - \\
\hline$P I_{E U}$ & - & - & $\begin{array}{c}0.31^{* * *} \\
(0.23-0.39)\end{array}$ & - \\
\hline$P I_{\text {Ideal }, E U}$ & - & - & - & $\begin{array}{c}-0.05 \\
(-0.18-0.08)\end{array}$ \\
\hline Groups & 54 & 54 & 27 & 27 \\
\hline Observations & 39,462 & 39,462 & 16,748 & 16,748 \\
\hline R-Squared & 0.27 & 0.27 & 0.19 & 0.19 \\
\hline $\mathrm{AIC}$ & 120,202 & 120,232 & 44,102 & 44,133 \\
\hline ICC & 0.129 & 0.208 & 0.131 & 0.130 \\
\hline
\end{tabular}

Note: table entries are standardized coefficients with confidence intervals from linear hierarchical models with random coefficient at the election-level. Dependent variable are estimated individual scale distortion parameters for the left-right dimension in Model (1) and Model (2), and for the EU integration dimension in Model (3) and Model (4). The models for the second dimension only consider the 2009 European elections. Significance stars: $* p<.05, * * p<.01, * * * p<.001$.

\section{Conclusions}

People are not elementary particles. They do not live in a vacuum. When dealing with citizens' attitudes and preferences, researchers should acknowledge that politics is subjectively constructed. Political events are interpreted in the light of one's own past experiences. Political actors are judged using personal frames of reference. The resulting individual perception of the political sphere arises holistically from the sense of self and the definition of reference groups. For this reason, the default research approach assuming that voters' lifelong baggage of experiences, networks, values and ideas does not contribute to the meaning attributed to political categories is no longer satisfying. 
The 2S-BAM algorithm can estimate and correct for voters' misperceptions within- and betweencountry. However, the cross-country comparability relies on the assumption that party membership in EP political groups can connect national political spaces. Moreover, the model did not consider the potential lack of measurement invariance induced by a longitudinal pan-European linear distortion of the political space. Thus, smarter designs are needed to better identify constructs that cannot be directly observed. Still, in most empirical applications dealing with political scales in a single country, researchers can assess to what extent differential item functioning is confounding their estimates comparing raw average party positions with the Aldrich-McKelvey estimates, implemented in the basicspace R package (Poole et al. 2016). Alternatively, they may use multiple scales measuring agreement with policy statements and estimate an IRT models to produce comparable latent policy scores. The latter strategy may provide an easier way to estimate comparable policy positions. In particular, issue items used to categorize political parties in Voting Advice Applications (e.g. Garzia et al. 2015), should be harmonized and implemented in comparative mass surveys, in order to achieve a common policy space for voters and parties.

Part of the confusion that has been attributed to the voters, suspected to be unable to perceive ideological differences, may depend on faulty methodologies and inappropriate analytical strategies. Voter perceptions are indeed integrated in the two main contemporary theories of electoral behaviour, spatial voting and social-psychological theories, and their role is also accounted for in studies on motivated reasoning as a strategy to reduce cognitive dissonance. Nevertheless, perceptual distortions are still unappreciated or disregarded in the majority of applied empirical studies. Yet, as this chapter has documented, differential understanding of political scales is a systematic trait interplaying with voters' orientations.

Political researchers have fallen in the trap of thinking that causal inference is hard, while descriptive inference is easy: while the former statement may be true, the latter might not. New research strategies are needed to map political preferences on comparable measurement scales. The attempts are growing: the Chapel Hill Expert Survey has introduced anchoring vignettes to bridge 
political experts across countries (Bakker et al. 2015), but similar strategies could be implemented in mass comparative surveys as well. On the one hand, comparable measures may clarify the relevance of issue voting, once item bias is accounted for, and, on the other hand, perceptual biases can be fruitfully analysed to explore the meaning of latent dimension. 


\section{References}

Achen, Christopher H, and Larry M Bartels. 2016. Democracy for Realists: Why Elections Do Not Produce Responsive Government. Princeton, N. J.: Princeton University Press.

Aldrich, John H., and Richard D. McKelvey. 1977. 'A Method of Scaling with Applications to the 1968 and 1972 Presidential Elections'. The American Political Science Review 71(1): 11130.

Andrich, David. 1988. Rasch Models for Measurement. Newbury Park: Sage Publications.

Baker, Frank B., and Seock-Ho Kim. 2004. Item Response Theory: Parameter Estimation Techniques, Second Edition. CRC Press.

Bakker, Ryan, Erica Edwards, et al. 2014. 'Anchoring the Experts: Using Vignettes to Compare Party Ideology across Countries’. Research \& Politics 1(3): 2053168014553502.

Bakker, Ryan et al. 2015. 'Measuring Party Positions in Europe The Chapel Hill Expert Survey Trend File, 1999-2010'. Party Politics 21(1): 143-52.

Bakker, Ryan, Seth Jolly, Jonathan Polk, and Keith T. Poole. 2014. 'The European Common Space: Extending the Use of Anchoring Vignettes'. The Journal of Politics 76(04): 1089-1101.

Barberá, Pablo. 2015. 'Birds of the Same Feather Tweet Together: Bayesian Ideal Point Estimation Using Twitter Data'. Political Analysis 23(1): 76-91.

Black, Duncan. 1948. 'On the Rationale of Group Decision-Making'. Journal of Political Economy 56(1): 23-34.

Bond, Trevor G., and Christine M. Fox. 2015. Applying the Rasch Model: Fundamental Measurement in the Human Sciences. Third edition. London: Taylor and Francis Group.

Bonica, Adam. 2014. 'Mapping the Ideological Marketplace'. American Journal of Political Science 58(2): 367-86.

Campbell, A., P. E. Converse, W. E. Miller, and D. E. Stokes. 1960. The American Voter. Chicago and London: The University of Chicago Press.

Clinton, Joshua, Simon Jackman, and Douglas Rivers. 2004. 'The Statistical Analysis of Roll Call Data'. American Political Science Review 98(2): 355-70.

Dalton, Russell J. 1985. 'Political Parties and Political Representation: Party Supporters and Party Elites in Nine Nations'. Comparative Political Studies 18(3): 267-99.

2008. 'The Quantity and the Quality of Party Systems Party System Polarization, Its Measurement, and Its Consequences'. Comparative Political Studies 41(7): 899-920.

Dalton, Russell J. 2017. 'Citizens' Representation in the 2009 European Parliament Elections'. European Union Politics 18(2): 188-211.

Dalton, Russell J., David M. Farrell, and Ian McAllister. 2011. Political Parties and Democratic Linkage: How Parties Organize Democracy. Oxford: Oxford University Press. 
Davidov, Eldad, Peter Schmidt, Jaak Billiet, and Bart Meuleman, eds. 2018. Cross-Cultural Analysis: Methods and Applications. Second edition. New York: Routledge, 2018.

Davis, Otto A., Melvin J. Hinich, and Peter C. Ordeshook. 1970. 'An Expository Development of a Mathematical Model of the Electoral Process'. American Political Science Review 64(02): 426-448.

De Angelis, Andrea. 2017. 'Bridging Troubled Water : Electoral Availability in European Party Systems in the Aftermath of the Great Recession (2009-2014) : An Application of Bayesian Ideal Point Estimation'. Doctoral Dissertation. http://cadmus.eui.eu//handle/1814/46986.

Downs, A. 1957. An Economic Theory of Democracy. New York: Harper \& Row.

Enelow, James M., and Melvin J. Hinich. 1984. The Spatial Theory of Voting: An Introduction. New York: Cambridge University Press.

Franklin, Mark N, Thomas Mackie, and Henry Valen. 1992. Electoral Change: Responses to Evolving Social and Attitudinal Structures in Western Countries. Cambridge: Cambridge University Press.

Garzia, Diego, Alexander H. Trechsel, Lorenzo De Sio, and Andrea De Angelis. 2015. 'Euandi: Project Description and Datasets Documentation'. Robert Schuman Centre for Advanced Studies Research Paper RCAS 2015(01). https://papers.ssrn.com/abstract=2553919 (July 2, 2018).

Gourlay, Annabelle et al. 2014. 'Using Vignettes in Qualitative Research to Explore Barriers and Facilitating Factors to the Uptake of Prevention of Mother-to-Child Transmission Services in Rural Tanzania: A Critical Analysis'. BMC Medical Research Methodology 14: 21.

Groseclose, Tim, Steven D. Levitt, and James M. Jr. Snyder. 1999. 'Comparing Interest Group Scores across Time and Chambers: Adjusted ADA Scores for the U.S. Congress'. American Political Science Review 93(01): 33-50.

Hare, Christopher et al. 2015. 'Using Bayesian Aldrich-McKelvey Scaling to Study Citizens' Ideological Preferences and Perceptions'. American Journal of Political Science 59(3): 75974.

Hix, Simon, Abdul Noury, and Gérard Roland. 2006. 'Dimensions of Politics in the European Parliament'. American Journal of Political Science 50(2): 494-511.

Hotelling, Harold. 1929. 'Stability in Competition'. The Economic Journal 39(153): 41.

Hutter, Swen, Edgar Grande, and Hanspeter Kriesi, eds. 2016. Politicising Europe: Integration and Mass Politics. Cambridge: Cambridge University Press.

King, Gary, and Jonathan Wand. 2007. 'Comparing Incomparable Survey Responses: Evaluating and Selecting Anchoring Vignettes'. Political Analysis 15(1): 46-66.

König, Thomas, Moritz Marbach, and Moritz Osnabrügge. 2013. 'Estimating Party Positions across Countries and Time-A Dynamic Latent Variable Model for Manifesto Data'. Political Analysis 21(4): 468-91. 
Kristensen, Nicolai, and Edvard Johansson. 2008. 'New Evidence on Cross-Country Differences in Job Satisfaction Using Anchoring Vignettes'. Labour Economics 15(1): 96-117.

Lachat, Romain. 2008. 'The Impact of Party Polarization on Ideological Voting'. Electoral Studies 27(4): 687-98.

Lauderdale, Benjamin E. 2010. 'Unpredictable Voters in Ideal Point Estimation'. Political Analysis 18(2): 151-71.

Lee, Jaehoon, Todd D. Little, and Kristopher J. Preacher. 2018. 'Methodological Issues in Using Structural Equation Models for Testing Differential Item Functioning'. In Cross-Cultural Analysis: Methods and Applications, European Association of Methodology, eds. Eldad Davidov, Peter Schmidt, Jaak Billiet, and Bart Meuleman. New York: Routledge.

Lelkes, Yphtach. 2016. 'Mass Polarization: Manifestations and Measurements'. Public Opinion Quarterly 80(S1): 392-410.

Lo, James, Sven-Oliver Proksch, and Thomas Gschwend. 2014. 'A Common Left-Right Scale for Voters and Parties in Europe'. Political Analysis 22(2): 205-23.

Markus, Gregory B., and Philip E. Converse. 1979. 'A Dynamic Simultaneous Equation Model of Electoral Choice'. The American Political Science Review 73(4): 1055-70.

McDonald, Michael D., and Ian Budge. 2005. Elections, Parties, Democracy: Conferring the Median Mandate. Oxford: Oxford University Press.

McFadden, Daniel L. 1976. 'Quantal Choice Analaysis: A Survey'. NBER Annals of Economic and Social Measurement 5(4): 363-90.

Osterlind, Steven J., Howard T. Everson, and Steven J. Osterlind. 2009. Differential Item Functioning. 2nd ed. Thousand Oaks, CA: SAGE.

Page, Benjamin I., and Calvin C. Jones. 1979. 'Reciprocal Effects of Policy Preferences, Party Loyalties and the Vote'. The American Political Science Review 73(4): 1071-89.

Poole, Keith T. 2005. Spatial Models of Parliamentary Voting. New York: Cambridge University Press.

. 2016. 'Recovering a Basic Space from Issue Scales in R'. Journal of Statistical Software 69(7).

Poole, Keith T., and Howard Rosenthal. 1997. Congress. A Political-Economic History of Roll Call Voting. New York and Oxford: Oxford University Press.

Rasch, George. 1960. Probabilistic Models for Some Intelligence and Attainment Tests. Chicago: University of Chicago Press.

Rohrschneider, Robert, and Stephen Whitefield. 2012. The Strain of Representation: How Parties Represent Diverse Voters in Western and Eastern Europe. First Edition. Oxford: Oxford University Press.

Sartori, Giovanni. 1976. Parties and Party Systems: A Framework for Analysis, Volume I.

Cambridge University Press. Cambridge: European Consortium for Political Research Press. 
Shor, Boris, Christopher Berry, and Nolan McCarty. 2010. 'A Bridge to Somewhere: Mapping State and Congressional Ideology on a Cross-Institutional Common Space'. Legislative Studies Quarterly 35(3): 417-48.

Slapin, Jonathan B., and Sven-Oliver Proksch. 2008. 'A Scaling Model for Estimating Time-Series Party Positions from Texts’. American Journal of Political Science 52(3): 705-22.

Treier, Shawn, and Simon Jackman. 2008. 'Democracy as a Latent Variable'. American Journal of Political Science 52(1): 201-17.

Van der Eijk, C., W. Van der Brug, M. Kroh, and M. Franklin. 2006. 'Rethinking the Dependent Variable in Voting Behavior: On the Measurement and Analysis of Electoral Utilities'. Electoral Studies 25: 424-47.

Vegetti, Federico. 2014. 'From Political Conflict to Partisan Evaluations: How Citizens Assess Party Ideology and Competence in Polarized Elections'. Electoral Studies 35: 230-41.

Volkens, Andrea et al., eds. 2013. Mapping Policy Preferences From Texts: Statistical Solutions for Manifesto Analysts. Oxford: Oxford University Press. 


\section{Appendix - A Two-Stage Bayesian Aldrich-McKelvey scaling algorithm}

This appendix provides a formal mathematical formulation for the model presented in section 3 . The model proceeds as follows: voters' reported perceptions of party positions $y_{i j}$ are considered as a linear function of party latent position $y_{j}^{*}$ :

$$
\begin{aligned}
& y_{i j} \sim N\left(\mu_{i j}, \sigma_{i j}^{2}\right) ; \quad \sigma_{i j}^{2}>0 \\
& \mu_{i j}=a_{i}+b_{i} y_{j}^{*} ; \quad a_{i}, b_{i}, y_{j}^{*} \in \mathbb{R} \\
& \text { (4.1c) } \sigma_{i j}^{2}=\sigma_{i}^{2} \sigma_{j}^{2} \text {. }
\end{aligned}
$$

Where: $i=\left\{1, \ldots, N_{k}\right\}$ indexes voters and $j=\left\{1, \ldots, J_{k}\right\}$ national political parties; $y_{i j}$ are voters' reported party positions with mean $\mu_{i j}$ and variance $\sigma_{i j}^{2} . \mu_{i j}$ is modelled as a function of three latent quantities: $a_{i}$ and $b_{i}$ are two latent distortions, with $a_{i}$ representing a location parameter, and $b_{i}$ a scale parameter; $y_{j}^{*}$ indicates the latent position of party $j$ (ideal point); finally, $\sigma_{i j}^{2}$ represents heteroskedastic-robust variance terms (Lauderdale 2010) capturing the dispersion around the mean of individual and party parameters.

The likelihood function is given by:

$$
\mathcal{L} \equiv p(\boldsymbol{Y} \mid \boldsymbol{\theta}) \propto \prod_{i=1}^{N} \prod_{j=1}^{J} \phi\left(\frac{y_{i j}-a_{i}-b_{i} y_{j}^{*}}{\sigma_{i j}^{2}}\right)
$$

Where: $\boldsymbol{Y}$ is the $\left[N_{k} \times J\right]$ matrix of observed party placement on the left-right scale, $\boldsymbol{\theta}=$ $\left\{\boldsymbol{\alpha}, \boldsymbol{\beta}, \boldsymbol{y}^{*}, \boldsymbol{\sigma}\right\}$ indicates the latent parameters, and $\phi(\cdot)$ is a standard normal density ${ }^{9}$. Assuming prior independence, and denoting prior density with $p(\boldsymbol{\theta})=p\left(\alpha, \beta, y^{*}, \sigma^{2}\right)$, we can express the joint posterior simply via Bayes rule:

\footnotetext{
${ }^{9}$ Bayesian AM models are inherently unidentified (Clinton, Jackman, and Rivers 2004). Additive, multiplicative and reflection aliasing are solved, following (Treier and Jackman 2008), imposing normalization and polarity constraints on the item distributions: the prior distributions for DIF distortion parameters are fairly uninformative: $a_{i}, b_{i} \sim N(0,25)$, while the party ideal points are standard normal, $y_{j}^{*} \sim N(0,1)$. Truncated uniform priors are used for variance parameters: $\sigma_{i}^{2}, \sigma_{j}^{2} \sim U(0,100)$.
} 


$$
\pi(\boldsymbol{\theta} \mid \boldsymbol{Y}) \propto p(\boldsymbol{\theta}) \cdot p(\boldsymbol{Y} \mid \boldsymbol{\theta})
$$

In the second stage, the model uses party membership in the political groups of the European Parliament as anchoring observations to estimate country-specific distortion parameters and to reconstruct the European Common Space enabling direct comparability across countries. Countryspecific party ideal points are estimated re-applying the A-M logic of the first-stage ${ }^{10}$ :

$$
\begin{aligned}
z_{k m[j]} & \sim N\left(\eta_{k m[j]}, \quad \sigma_{k m}^{2}\right) ; \quad \sigma_{k m}^{2}>0 \\
\eta_{k m[j]} & =c_{k}+d_{k} z_{m}^{*} ; \quad c_{i}, d_{i}, z_{m}^{*} \in \mathbb{R} \\
\sigma_{k m}^{2} & =\sigma_{k}^{2} \cdot \sigma_{m}^{2} .
\end{aligned}
$$

Where: $k=\{1, \ldots, K\}$ indexes countries, and $m=\left\{1, \ldots, M_{t}\right\}$ indexes EP political groups; $\eta_{j k m}$ represents the mean of the distribution of the ideal points, and is modelled as a function of three latent parameters: $c_{k}$ is a country-specific lateral shift distortion parameter; $d_{k}$ is a countryspecific scale distortion. The term $\sigma_{k m}^{2}$ represents heteroskedastic-robust variances ${ }^{11}$. The likelihood function is given by:

$$
\mathcal{L} \equiv p(\boldsymbol{Z} \mid \boldsymbol{\theta}) \propto \prod_{j=1}^{J_{k}} \prod_{k=1}^{K} \prod_{m=1}^{M} \phi\left(\frac{z_{k m[j]}-c_{k}-d_{k} z_{m}^{*}}{\sigma_{k m}^{2}}\right)
$$

Where: $\boldsymbol{Z}$ is the $J_{K} \times M_{t}$ matrix of observed party placement on the left-right scale, $\boldsymbol{\theta}=\left\{\boldsymbol{\gamma}, \boldsymbol{\delta}, \boldsymbol{z}^{*}, \boldsymbol{\sigma}\right\}$ represents the latent parameters, and $\phi(\cdot)$ is a standard normal density. Applying the same identification constrains of the first stage, assuming prior independence and defining the prior density as $p(\boldsymbol{\theta})=p\left(\gamma, \delta, z^{*}, \sigma^{2}\right)$, we can finally obtain the joint posterior via Bayes rule as:

$$
\pi(\boldsymbol{\theta} \mid \boldsymbol{Z}) \propto p(\boldsymbol{\theta}) \cdot L(\boldsymbol{Z} \mid \boldsymbol{\theta})
$$

\footnotetext{
10 This is equivalent to the first-stage model of voters' perceptions. I replace the notation of the latent scores from $y_{j}^{*}$ with $z_{j k m}$ to emphasize that the same quantity that was previously representing a parameter is now considered as data.

11 The only difference with the first-stage indexing: the second stage relies on a hierarchical extension of the BAM algorithm. The reason is straightforward: voters are asked to place each party only once, but in various countries there is more than one party belonging to the same EP group. Thus, party positions are explicitly considered as nested within countries and within EP groups, and this is indicated with nested indexing: $k m[j]$.
} 
Once the distortion parameters have been estimated, we can map all country-specific latent positions into fully comparable values mapped on the European Common Space using simple linear transformations:

$$
z_{j}^{*}=\frac{z_{j k}-a_{k}}{b_{k}}
$$

The 2S-BAM model improves upon previous approaches developing a hierarchical adaptation of classic Bayesian AM scaling, which allows: 1) including cases with countries missing a national party for one or more EP groups, as well as countries with more than one party for each EP group; 2) estimating positions and related uncertainty measures for EP political groups; 3) estimating uncertainty measures for the country-specific distortion parameters. These desirable properties are not allowed in a frequentist bridging procedure developed in Groseclose et al. (1999) and applied in (Lo et al. 2014). The hierarchical adaptation of the AM model can be a useful extension in other settings. 